\title{
Dependence of Nodal Sodium Channel Clustering on Paranodal Axoglial Contact in the Developing CNS
}

\author{
Matthew N. Rasband, ${ }^{1}$ Elior Peles, ${ }^{3}$ James S. Trimmer, ${ }^{4}$ S. Rock Levinson, ${ }^{5}$ Samuel E. Lux, ${ }^{6}$ and \\ Peter Shrager ${ }^{1,2}$ \\ Departments of ${ }^{1}$ Biochemistry and Biophysics and ${ }^{2}$ Neurobiology and Anatomy, University of Rochester Medical Center, \\ Rochester, New York 14642, ${ }^{3}$ The Weizmann Institute of Science, Rehovot, Israel 76100, ${ }^{4}$ Department of Biochemistry \\ and Cell Biology, State University of New York, Stony Brook, New York 11794, 5Department of Physiology, University of \\ Colorado, Denver, Colorado 80262, and 6Hematology/Oncology Division, Department of Medicine, Children's Hospital, \\ Boston, Massachusetts 02115
}

$\mathrm{Na}^{+}$channel clustering at nodes of Ranvier in the developing rat optic nerve was analyzed to determine mechanisms of localization, including the possible requirement for glial contact in vivo. Immunofluorescence labeling for myelin-associated glycoprotein and for the protein Caspr, a component of axoglial junctions, indicated that oligodendrocytes were present, and paranodal structures formed, as early as postnatal day 7 (P7). However, the first $\mathrm{Na}^{+}$channel clusters were not seen until P9. Most of these were broad, and all were excluded from paranodal regions of axoglial contact. The number of detected $\mathrm{Na}^{+}$ channel clusters increased rapidly from P12 to P22. During this same period, conduction velocity increased sharply, and $\mathrm{Na}^{+}$ channel clusters became much more focal. To test further whether oligodendrocyte contact directly influences $\mathrm{Na}^{+}$channel distributions, nodes of Ranvier in the hypomyelinating mouse Shiverer were examined. This mutant has

The node of Ranvier in the mammalian myelinated nerve fiber represents one of the most specialized membrane domains in the body. $\mathrm{Na}^{+}$channels are clustered in very high density within the nodal gap (Shrager, 1989; Novakovic et al., 1996; Vabnick et al., 1996), whereas voltage-dependent $\mathrm{K}^{+}$channels are segregated in juxtaparanodal regions, beneath overlying myelin (Chiu and Ritchie, 1980; Wang et al., 1993; Mi et al., 1995). Nodal $\mathrm{Na}^{+}$ channels are the source of inward current that allows for both rapid saltatory conduction and regeneration of the action potential amplitude during signal propagation. These channels are spatially separated from $\mathrm{K}^{+}$channels by the paranode, the region where myelin lamellae terminate as cytoplasmic loops that abut the axon, forming axoglial junctions (Schnapp et al., 1976; Rasband et al., 1998). These junctions are thought to create a highresistance barrier to the flow of ionic current (Chiu and Ritchie, 1981).

\footnotetext{
Received April 29, 1999; revised June 23, 1999; accepted June 23, 1999.

This work was supported by National Institutes of Health Grants NS17965, NS34383, NS34375, DK34083, and HL32262, National Multiple Sclerosis Society Grant RG-2687, and a Pilot Research Award. E.P. is an incumbent of the Madeleine Haas Russell Career Development Chair. We are grateful to Dr. Melitta Schachner for the anti-MAG antibody.

Correspondence should be addressed to Dr. Peter Shrager, Department of Neurobiology and Anatomy, Room 4-5428, Box 603, University of Rochester Medical Center, 601 Elmwood Avenue, Rochester, NY 14642.

Dr. Rasband's present address: Department of Biochemistry and Cell Biology, State University of New York, Stony Brook, NY 11794.

Copyright (C) 1999 Society for Neuroscience 0270-6474/99/197516-13\$05.00/0
}

oligodendrocyte-ensheathed axons but lacks compact myelin and normal axoglial junctions. During development $\mathrm{Na}^{+}$channel clusters in Shiverer mice were reduced in numbers and were in aberrant locations. The subcellular location of Caspr was disrupted, and nerve conduction properties remained immature. These results indicate that in vivo, $\mathrm{Na}^{+}$channel clustering at nodes depends not only on the presence of oligodendrocytes but also on specific axoglial contact at paranodal junctions. In rats, ankyrin-3/G, a cytoskeletal protein implicated in $\mathrm{Na}^{+}$channel clustering, was detected before $\mathrm{Na}^{+}$channel immunoreactivity but extended into paranodes in non-nodal distributions. In Shiverer, ankyrin-3/G labeling was abnormal, suggesting that its localization also depends on axoglial contact.

Key words: sodium channels; node of Ranvier; optic nerve; development; Shiverer; ankyrin

Many aspects of the developmental mechanisms responsible for these nodal specializations remain unknown. Central to this issue is the question of whether the neuron or neighboring glial cells direct the process, and a number of recent studies have addressed this topic. Kaplan et al. (1997) reported $\mathrm{Na}^{+}$channel clustering in cultured CNS retinal ganglion cells in the absence of glial contact. Their results suggested that oligodendrocytes secreted a soluble factor that initiated clustering, and that the location of nodes was intrinsically determined by the axonal cytoskeleton. Other studies have also described various forms of $\mathrm{Na}^{+}$channel clustering without any direct glial association (England et al., 1990; Johnston et al., 1996; Deerinck et al., 1997; Vabnick et al., 1997). In contrast, results from experiments on sciatic nerves during both development (Vabnick et al., 1996) and remyelination (Dugandzija-Novakovic et al., 1995) have suggested that Schwann cell contact and myelination are required for nodal $\mathrm{Na}^{+}$ channel clustering. It was proposed that glia, not neurons, determine the location of nodes of Ranvier and initiate ion channel clustering. These conflicting ideas have recently been reviewed (Salzer, 1997; Vabnick and Shrager, 1998).

In the present study, we have used immunocytochemistry and electrophysiology to investigate in detail, for the first time, $\mathrm{Na}^{+}$ channel clustering and node formation during development of CNS myelinated nerve fibers in vivo. The results suggest that paranodal structures play an essential role in determining $\mathrm{Na}^{+}$ channel distributions. 


\section{MATERIALS AND METHODS}

Primary antibodies. For $\mathrm{Na}^{+}$channel localization, both rabbit polyclonal and mouse monoclonal antibodies were used. These antibodies were generated against similar synthetic peptides, each containing the sequence TEEQKKYYNAMKKLGSKK, a highly conserved segment of the intracellular III-IV loop. A cysteine residue was added to the C (polyclonal) or $\mathrm{N}$ (monoclonal) terminus of this segment for linkage to keyhole limpet hemocyanin $(\mathrm{KLH})$. The pan- $\mathrm{Na}^{+}$channel polyclonal antibody was raised in rabbits, followed by affinity purification, and has been described elsewhere (Dugandzija-Novakovic et al., 1995). It was used at a dilution of 1:80. The pan- $\mathrm{Na}^{+}$channel monoclonal antibody K58/35 was generated by immunizing mice with the peptide-KLH conjugate. Production of hybridoma cell lines and screening of hybridoma culture supernatants by ELISA against the peptide-BSA conjugate were as described (Bekele-Arcuri et al., 1996). ELISA-positive clones were screened by immunofluorescence staining of rat optic nerve and of transiently transfected COS-1 cells expressing the rat $\mathrm{mI} / \mathrm{SkmI}$ adult muscle $\mathrm{Na}^{+}$channel (Trimmer et al., 1989). The K58/35 hybridomas were grown in BALB/c mice for production of ascites fluid. K58/35 IgG1s were purified by ammonium sulfate precipitation followed by DEAE chromatography, as described (Trimmer et al., 1985). The purified antibody was used at a dilution of $0.7 \mu \mathrm{g} / \mathrm{ml}$. The polyclonal anti-Caspr was generated against a bacterial fusion protein containing the cytoplasmic domain and was used at a dilution of 1:2500 (Peles et al., 1997). The polyclonal anti-ankyrin-3/G (anti-ankyrin-3; Peters et al., 1995) was used at a dilution of 1:400. Anti-myelin-associated glycoprotein (anti-MAG) monoclonal antibodies were prepared as described by Poltorak et al. (1987) and used at a dilution of 1:250.

Immunofluorescence. Optic nerves from mice (Shiverer and littermate controls, $\mathrm{C} 3 \mathrm{HeB} / \mathrm{FeJ}-\mathrm{MBPshi}$ J Jackson Laboratory, Bar Harbor, ME) or Lewis rats were dissected immediately after animals were killed. Nerves were fixed in $4 \%$ paraformaldehyde in $0.1 \mathrm{M}$ phosphate buffer (PB), $\mathrm{pH}$ 7.2 , for $30 \mathrm{~min}$, cryoprotected in $20-30 \%$ sucrose, frozen in OCT mounting medium (Miller), and cut in $10-\mu \mathrm{m}$-thick sections. Sections were placed in $0.1 \mathrm{M} \mathrm{PB}$, spread on gelatin-coated coverslips, and allowed to air dry. The tissue was then permeabilized for $2 \mathrm{hr}$ in $0.1 \mathrm{M} \mathrm{PB}, \mathrm{pH} 7.4$, containing $0.3 \%$ Triton X-100 and $10 \%$ goat serum (PBTGS). In all steps involving antibodies, samples were washed three times for 5 min each with PBTGS between succeeding steps. Sections were incubated overnight with primary antibodies diluted in PBTGS. For double labeling, the tissue was incubated with the second primary antibody for a minimum of $2 \mathrm{hr}$. Incubation with primary antibodies was followed by application of fluorophore-conjugated secondary antibodies for $1 \mathrm{hr}$. The secondary antibodies were a goat-anti-rabbit IgG conjugated to FITC (1:300; Sigma, St. Louis, MO), or goat anti-mouse antibodies conjugated to TRITC (1:200; Sigma) or Cy-3 (1:2,000; Accurate Chemicals, Westbury, NY). Finally, labeled cryosections were rinsed consecutively in PBTGS, $0.1 \mathrm{M}$ $\mathrm{PB}$, and $0.05 \mathrm{M} \mathrm{PB}$ for $5 \mathrm{~min}$ each. The samples were then air-dried and mounted on slides with an anti-fade mounting medium. In some experiments, both primary antibodies were rabbit polyclonal. In this situation, the tissue was first incubated with $\mathrm{Na}^{+}$channel antibodies, followed by addition of secondary goat anti-rabbit Fab-FITC (Accurate) at a dilution of 1:25. The sections were then incubated with anti-Caspr, and finally, a secondary goat anti-rabbit Fab-Cy-3 (Accurate) was applied at a dilution of 1:2000-4000. Between steps, the samples were washed at least six times. Immunolabeled slides were examined on a Nikon Microphot fluorescence microscope fitted with a C4742-95 cooled CCD camera (Hamamatsu). Digitized images were passed to a laboratory computer for later analysis using Image Pro (Media Cybernetics). Wherever statistics are used, results are given \pm SD.

Electrophysiology. Optic nerves were dissected and placed in a recording chamber that was continuously perfused, oxygenated, and temperature-regulated. The standard Locke's solution contained (in mM): $\mathrm{NaCl} 154, \mathrm{KCl}$ 5.6, $\mathrm{CaCl}_{2}$ 2, D-glucose 5, and HEPES 10, $\mathrm{pH}$ 7.4. For stimulation and recording of action potentials, each end of the nerve was drawn into a suction electrode (Stys et al., 1991). Stimuli consisted of $50 \mu \mathrm{sec}$ pulses with amplitudes that were adjusted to $\sim 10 \%$ above the level required for a maximum response. Compound action potentials (CAPs) were amplified, digitized, recorded, and analyzed on a laboratory computer. Amplitudes were arbitrary in these external electrode recordings and are thus not included in figures; the primary information is in the shape and duration of the signals. Conduction velocity was calculated as the length of the nerve divided by the time to the first peak amplitude of the CAP. In some experiments using mice, compound action poten- tials were first measured, and then nerves were fixed and used for labeling experiments.

\section{RESULTS}

\section{Is $\mathrm{Na}^{+}$channel clustering dependent on glial contact?}

Our initial experiments were designed to distinguish among different hypotheses for the involvement of glia in $\mathrm{Na}^{+}$channel clustering. Using immunofluorescence microscopy and electrophysiology we measured the distribution and function of $\mathrm{Na}^{+}$ channels during development of the rat optic nerve. To determine the extent of myelination, axons were double-labeled to detect MAG and Caspr/Paranodin (contactin-associated protein; Menegoz et al., 1997; Peles et al., 1997). At the earliest stage of development examined, postnatal days 5-6 (P5-P6), MAG immunoreactivity was not seen (Fig. $1 a$ ). Similarly, neither $\mathrm{Na}^{+}$ channels nor Caspr were detected by immunocytochemistry (data not shown). In the optic nerve, oligodendrocyte development and myelination begin at the start of the second postnatal week (Skoff et al., 1976; Black et al., 1982), with MAG expressed first in perinuclear cytoplasmic regions and later on the surface of the cell body and extensive processes. In contrast to its expression in Schwann cells in the PNS, MAG is seen before ensheathement (Bartsch et al., 1989).

From P5 to P7, oligodendroglia have 20-40 longitudinal processes that extend along the length of axons for 50-100 $\mu \mathrm{m}$ (Butt and Ransom, 1993). Figure $1 b$ shows a region of optic nerve labeled for MAG immunoreactivity. Cell bodies with perinuclear, cytoplasmic MAG staining are abundant and distributed randomly throughout the nerve (Fig. 1b, arrowhead). Some oligodendrocytes had MAG-labeled processes that extended longitudinally along axons. A similar region at P8 is shown in Figure $1 d$. Importantly, however, $\mathrm{Na}^{+}$channel clusters were not detected (Fig. 1c). Furthermore, in some axons as early as P7, focal Caspr immunoreactivity was present in short segments that overlapped with the edges of MAG-labeled processes (Fig. 1e,f, arrows). Because Caspr is a neuronal component of the paranodal septate junctions between axons and myelinating glial cells (Einheber et al., 1997), these observations suggest that these specialized structures begin to form at very early stages of myelination. Similarly, Wiggins et al. (1988) have shown in electron microscopic studies that axoglial junctions in the optic nerve form after one full rotation of mesaxon. Analyzing random fields of view $\left(\mathrm{FOV} ; 1 \mathrm{FOV}=2970 \mu \mathrm{m}^{2}\right.$ ) from Caspr-positive cryosections at P7, we found 1.5 \pm 0.9 Caspr-labeled sites (regions with at least one paranode labeled) per FOV $(n=8)$. However, $\mathrm{Na}^{+}$channel clusters were not detected, although many cryosections (each with $>200$ FOVs), were thoroughly scanned. Thus, despite the presence of numerous oligodendrocytes, some at early stages of myelination, $\mathrm{Na}^{+}$channel clustering remained below the level required for identification via immunofluorescence.

\section{Early $\mathrm{Na}^{+}$channel clustering and node formation}

$\mathrm{Na}^{+}$channel clusters were first detected beginning at P9-P10. The relationship between paranode formation and $\mathrm{Na}^{+}$channel clustering was investigated by double-labeling with Caspr and $\mathrm{Na}^{+}$channel antibodies. In some cases, intense Caspr immunoreactivity was observed in both paranodes, whereas at other sites, only a single paranode was labeled. When both paranodes were labeled, $100 \%(n=36)$ of these sites also had focal $\mathrm{Na}^{+}$channel immunostaining in the nodal gap (Fig. $2 a$ ). When only one paranode was labeled by anti-Caspr, 65\% (79 of 121) had no detectable $\mathrm{Na}^{+}$channel staining (Fig. 2c). The remaining 35\% of 

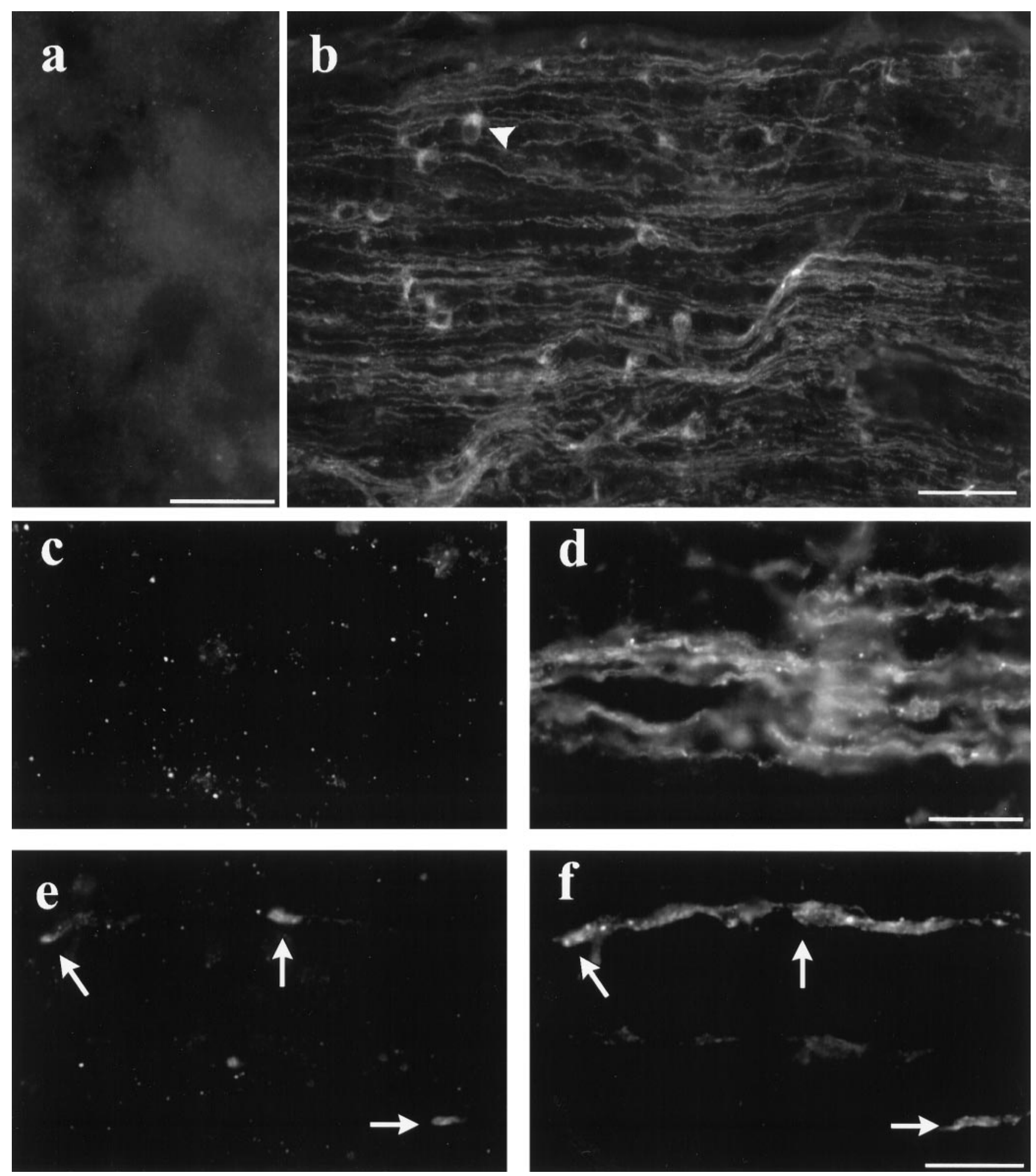

Figure 1. Expression of oligodendrocyte, myelin, and axoglial components before the detection of $\mathrm{Na}^{+}$channel clusters. $a$, At P6, MAG-positive cells were not detected. $b$, A P7 optic nerve cryosection labeled for MAG. $c, d$, At P8, $\mathrm{Na}^{+}$channel immunoreactivity was undetectable (c) despite the presence of many MAG-positive oligodendrocyte processes $(d)$. e, $f$, A P7 optic nerve section double-labeled for Caspr $(e)$ and MAG $(f)$ immunoreactivity. Caspr is found at the edges of MAG labeled processes (arrows). Scale bars: $a, c, d, e, f, 10 \mu \mathrm{m} ; b, 50 \mu \mathrm{m}$.

singly labeled paranodes had broad regions of $\mathrm{Na}^{+}$channel immunofluorescence with an intensity that was highest adjacent to the Caspr-labeled paranode, and then tapered off (Fig. 2b, arrowhead). $\mathrm{Na}^{+}$channel and Caspr immunoreactivity never overlapped, indicating that the distributions of these neuronal proteins are stringently regulated, even during early stages of node formation. These distributions reflect the location of overlying oligodendrocyte processes because Caspr is part of the 

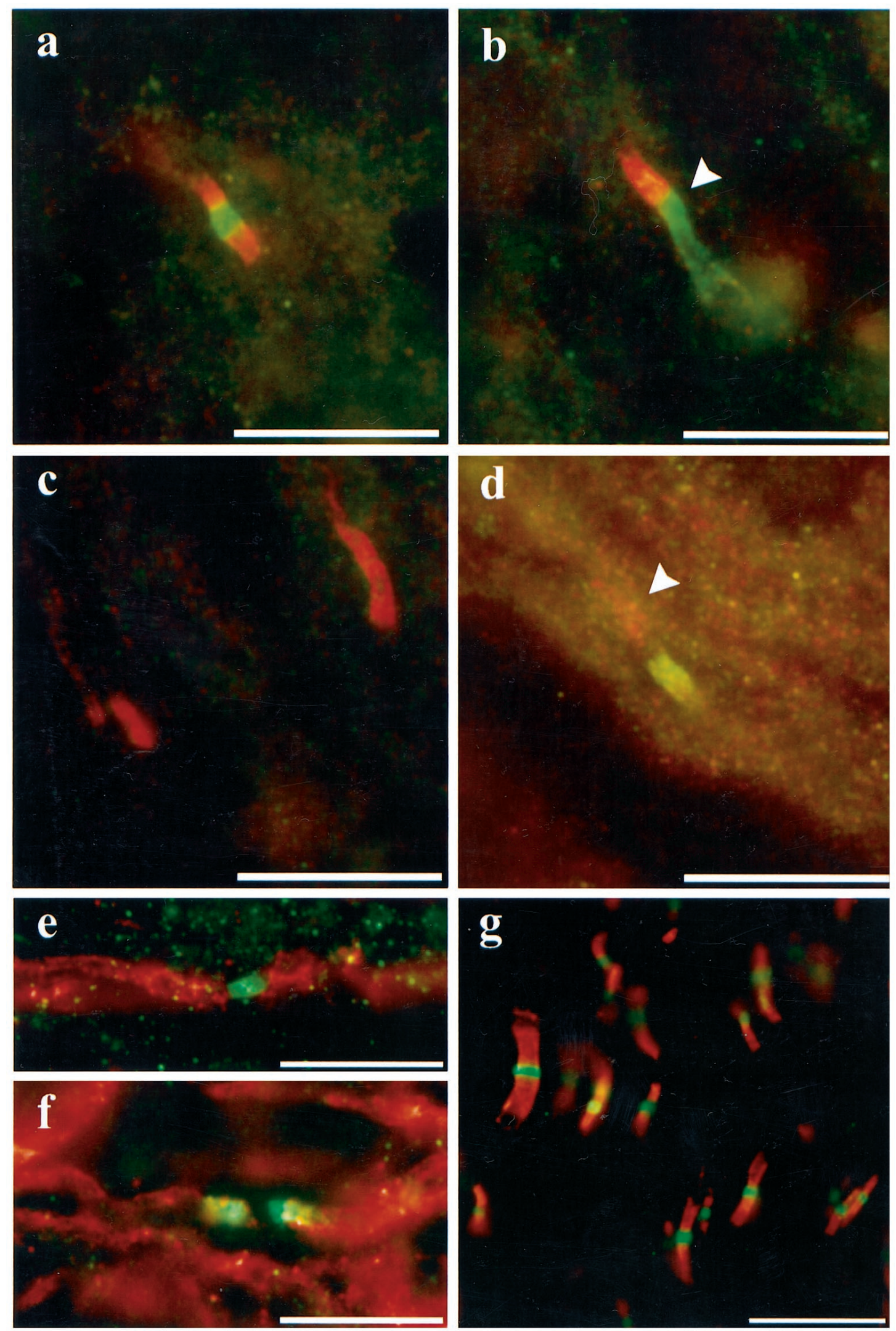

Figure 2. Early $\mathrm{Na}^{+}$channel clustering and node formation. $a-d$, $\mathrm{P} 9$ optic nerves show four different patterns of $\mathrm{Na}^{+}$channel (green) and Caspr (red) distributions at early stages of development (see Results). $e$, P10 section labeled for $\mathrm{Na}^{+}$channels (green) and MAG (red). $f$, P10 optic nerve double-labeled for Caspr ( green) and MAG (red) immunoreactivity. g, Adult optic nerve axons double-labeled for Caspr (red) and $\mathrm{Na}^{+}$channels ( green). Scale bars, $10 \mu \mathrm{m}$ 

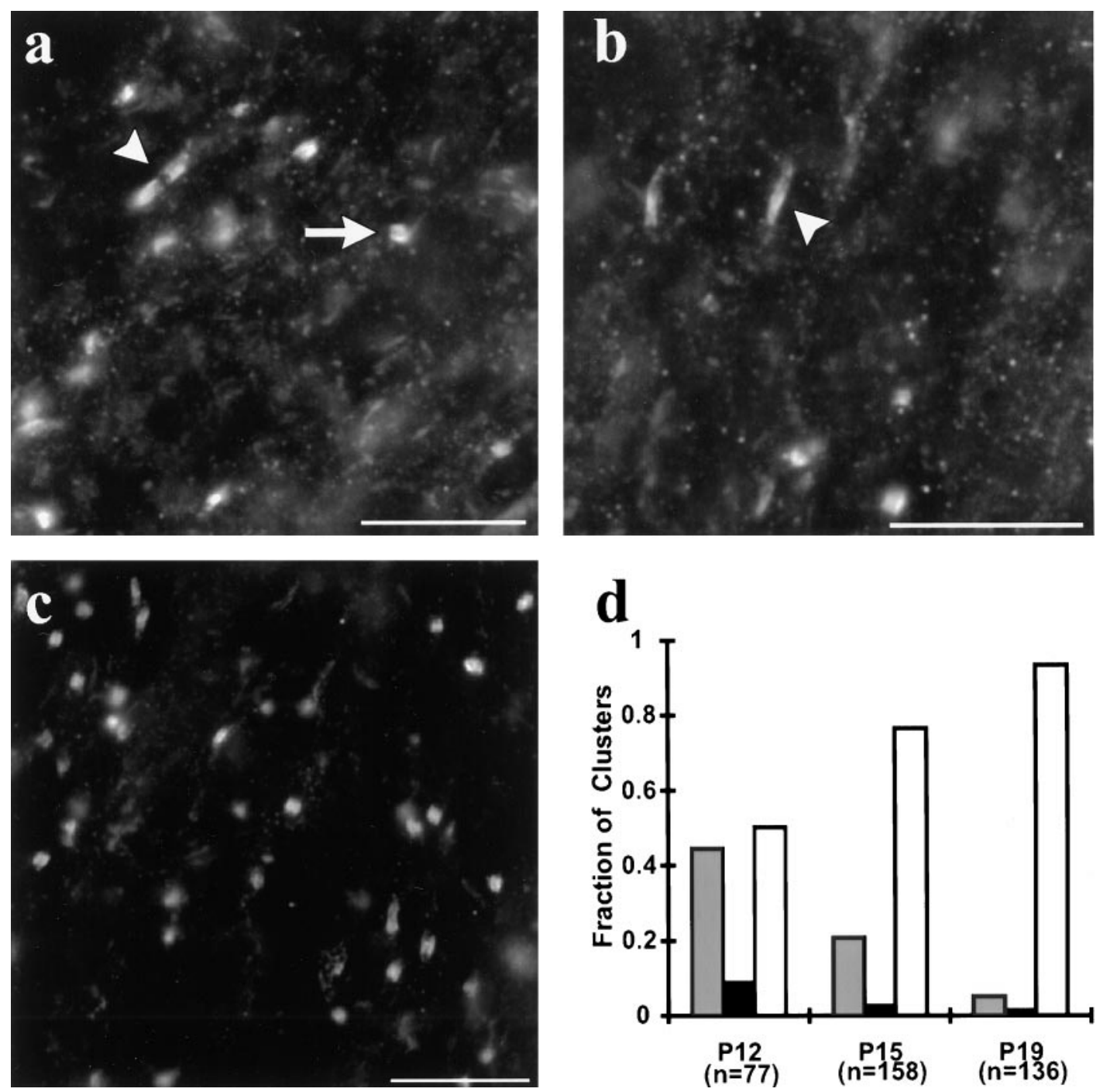

Figure 3. $\mathrm{Na}^{+}$channel distributions during development. $a, b, \mathrm{Na}^{+}$channel clusters at $\mathrm{P} 15$, in three different distributions: focal ( $a$, arrow), binary $(a$, arrowhead), or broad (b,arrowhead). $c$, At P19, the majority of $\mathrm{Na}^{+}$channel clusters were focal, and there was a marked increase in the number of clusters per FOV. $d$, The fraction of $\mathrm{Na}^{+}$channel clusters in each category at P12, P15, and P19. Gray bars, Broad; black bars, binary; white bars, focal. Scale bars, $10 \mu \mathrm{m}$.

paranode. Twelve percent (14 of 118) of sites that stained for $\mathrm{Na}^{+}$channel clustering had only weak or even undetectable Caspr immunoreactivity (Fig. 2d, arrowhead). On the other hand, at this stage $\mathrm{Na}^{+}$channel clusters were always adjacent to MAGlabeled oligodendrocyte processes at early nodes of Ranvier (Fig. $2 e$ ). Paranodal regions were formed by Caspr-labeled sites at the edges of MAG-positive processes (Fig. 2f). Not all Caspr-stained regions were associated with $\mathrm{Na}^{+}$channel clusters. At P10, fewer than two $\mathrm{Na}^{+}$channel clusters per FOV $(n=11)$ were detected, but an average of five Caspr-labeled sites were present $(n=4)$. By $\mathrm{P} 12, \mathrm{Na}^{+}$channel clustering was much more frequent, with clusters found exclusively in MAG-labeled regions (data not shown). However, because the axon density within cryosections is high (average axonal diameter at P11 is $0.4 \mu \mathrm{m}$; Foster et al., 1982), and MAG immunofluorescence is extensive, we could not always associate a $\mathrm{Na}^{+}$channel cluster with a particular single axon to look for MAG-positive processes.

During the next week, from P15 to P19, the number of $\mathrm{Na}^{+}$ channel clusters increased dramatically from an average of 17 to 41 clusters per FOV ( $n=10$ and 11, respectively). The number of
Caspr-labeled sites exceeded the number of $\mathrm{Na}^{+}$channel clusters throughout the early developmental stages. During the period of rapid formation of $\mathrm{Na}^{+}$channel clusters (P12-P19), we found that these sites fell into three distinct classes: (1) broad aggregates of $\mathrm{Na}^{+}$channels that extended $>1.5 \mu \mathrm{m}$ in length, (2) pairs of $\mathrm{Na}^{+}$channel clusters (termed binary) with central gaps in immunoreactivity (binary clusters also extended more than $1.5 \mu \mathrm{m}$ ), and (3) focal zones $<1.5 \mu \mathrm{m}$ long at relatively mature nodes of Ranvier. Figure $3 a$ shows binary (arrowhead) and focal (arrow) clusters, and Figure $3 b$ illustrates a broad region (arrowhead) from P15 rat optic nerves. Note that many of these zones are characterized by double lines of immunofluorescence, indicative of surface expression. The increase in spatial frequency of focal clusters at P19 is evident in Figure $3 c$. In Figure $3 d$ we plot the fraction of total sites corresponding to each cluster type. Over the period P12-P19, the frequency of broad and binary clusters fell, whereas that of focal sites rose. Both this pattern and the distributions described are reminiscent of those seen in the PNS during development (Vabnick et al., 1996) and remyelination (Dugandzija-Novakovic et al., 1995). However, as in PNS devel- 
opment, the number of binary clusters was quite small at all stages. We conclude that at most nodes of Ranvier in the optic nerve, $\mathrm{Na}^{+}$channels are first found in rather broad zones and condense into highly focal regions as myelination progresses.

\section{Adult distributions}

By 2 months of age, all nodal regions were characterized by a focal $\mathrm{Na}^{+}$channel cluster bordered by a pair of Caspr-positive paranodes, a pattern that was independent of axon diameter (Fig. $2 g$ ). The clustering of $\mathrm{Na}^{+}$channels and Caspr over the first 2 months and in adults ( $>3$ months) is plotted in Figure $4 a . \mathrm{Na}^{+}$ channel clustering occurred within a narrow window of time from P9 to P22. It is noteworthy that the rise in frequency of Casprlabeled zones preceded that of $\mathrm{Na}^{+}$channels by $\sim 2 \mathrm{~d}$. Both $\mathrm{Na}^{+}$ channel and Caspr values peaked at nearly the same time and then fell slightly to their final adult levels. This decrease may reflect the continuing growth of the animal with a consequent increase in internodal lengths (Hildebrand and Waxman, 1984).

$\mathrm{Na}^{+}$channel cluster length was also measured (Fig. 4b) and can be seen clearly to decrease during the period corresponding to rapid cluster formation. This result shows that the aggregation of $\mathrm{Na}^{+}$channels is not initially restricted solely to sites predestined to become nodal gaps but rather begins in broad distributions that later condense on average threefold as myelination progresses. The range of cluster lengths at early stages was wide, with some sites condensing as much as fivefold during maturation. The gap length between Caspr-positive paranodes also decreased over this same period, from an average of $1.7 \pm 0.7(n=18) \mu \mathrm{m}$ at P10 to $0.9 \pm 0.3(n=47) \mu \mathrm{m}$ in the adult, the latter value corresponding closely to the length of adult $\mathrm{Na}^{+}$channel clusters. Thus, maturation of nodes of Ranvier includes a reduction in the width of the gap between paranodes. However, at the earliest stages of development, Caspr gap lengths cannot be compared directly with $\mathrm{Na}^{+}$channel cluster length because the former are biased to shorter values, because only sites with both paranodes labeled could be measured. $\mathrm{Na}^{+}$channel clusters on the other hand included many (a majority at P9) bordered by only a single Caspr-positive zone.

\section{Conduction velocities in the developing optic nerve}

CAPs in the rat optic nerve were recorded at several ages, and conduction velocities were calculated for the fastest component. Figure $4 c$ shows the results of these measurements at three different temperatures: $37^{\circ} \mathrm{C}(\boldsymbol{\Delta}), 30^{\circ} \mathrm{C}(\boldsymbol{\square})$, and $26^{\circ} \mathrm{C}(\diamond)$. Before the detection of any $\mathrm{Na}^{+}$channel immunoreactivity at nodes of Ranvier, propagation was very slow $(<1 \mathrm{~m} / \mathrm{sec})$, and the CAP had a single component (Fig. 4d, P2). Significantly, the conduction velocity improved precisely during the period when maximal change occurred in both the number of $\mathrm{Na}^{+}$channel clusters per FOV and the average length of individual nodes. CAP shape also changed over this time, developing three broad but distinct peaks by P16 (Fig. 4d). The three components seen in this CAP are also present in the adult rat optic nerve (Fig. 4d). This feature has been described elsewhere (Foster et al., 1982) and most likely represents the different populations of $\mathrm{W}, \mathrm{X}$, and $\mathrm{Y}$ retinal ganglion cells (Fukuda et al., 1984; Hsiao et al., 1984). Thus, significant functional changes accompany the maturation of $\mathrm{Na}^{+}$channel clustering and paranode formation in the optic nerve.

\section{Ankyrin-3/G at nodes of Ranvier during development}

The cytoskeletal protein ankyrin-3/G (also known as ank3 and ankyrin $_{\mathrm{G}}$; Kordeli et al., 1995; Peters et al., 1995) has been shown to bind to $\mathrm{Na}^{+}$channels in vitro (Srinivasan et al., 1988) and is a
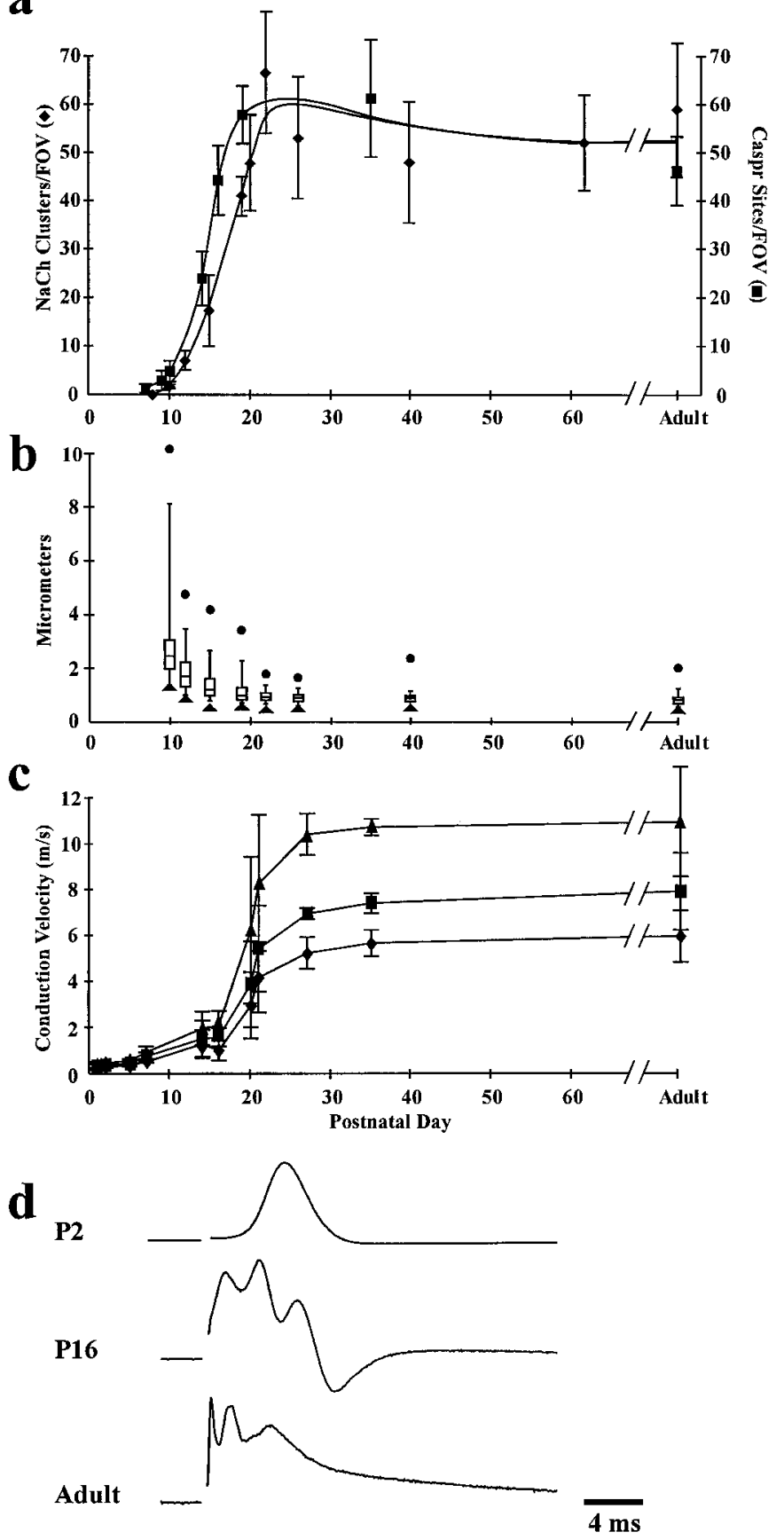

Figure 4. Functional and morphological changes during development. $a$, Number of $\mathrm{Na}^{+}$channel clusters per FOV $(\bullet)$ and the number of Caspr sites per FOV (ם) plotted at different ages. An average of 11 FOVs were analyzed at each age for $\mathrm{Na}^{+}$channel clusters and 10 for Caspr-positive sites. Curves were drawn by eye to indicate trends. $b$, Length of $\mathrm{Na}^{+}$ channel clusters during development graphed as a box plot. At each data point, the box shows the middle half of the data between the 25th and 75th percentiles, with the central line in the box representing the median. The vertical lines correspond to the range between the 5th and 95th percentiles. The maximum $(\bullet)$ and minimum $(\boldsymbol{\Delta})$ lengths are also shown. $c$, Conduction velocities measured as a function of age at three temperatures: $37^{\circ} \mathrm{C}$ $(\boldsymbol{\Delta}), 30^{\circ} \mathrm{C}(\boldsymbol{\square})$, and $26^{\circ} \mathrm{C}(\bullet) . d$, CAPs during development, recorded from P2, P16, and adult optic nerves. Amplitudes are arbitrary in these external recordings. Error bars indicate SD. 

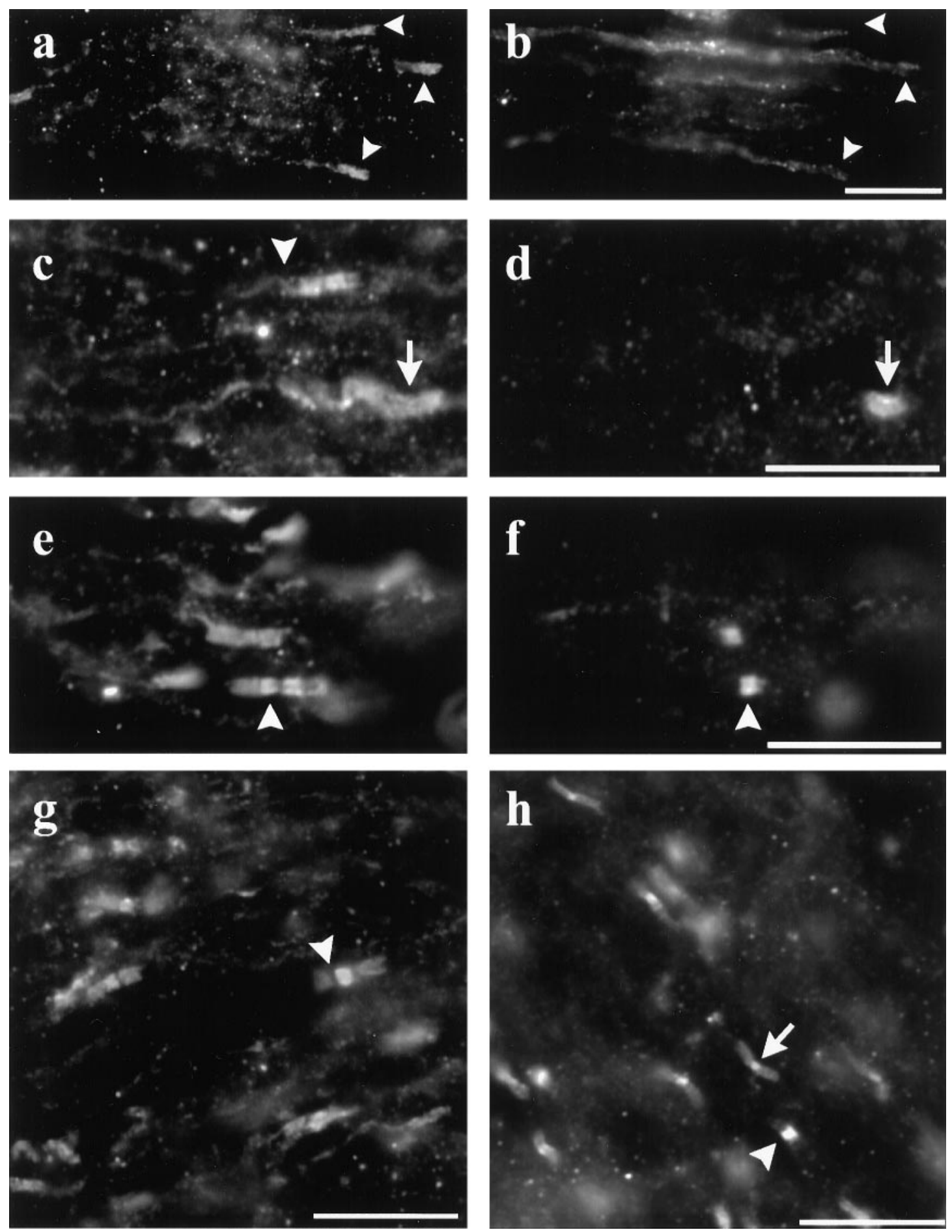

Figure 5. Ankyrin-3/G distributions in rat optic nerves during development. $a, b, \mathrm{~A}$ P7 optic nerve shows that ankyrin-3/G ( $a$, arrowheads) is found at the edges of MAG-labeled oligodendrocyte processes (b, arrowheads). $c, d$, A P9 rat optic nerve double-labeled for ankyrin-3/G $(c)$ and Na ${ }^{+}$channels $(d)$ illustrates a site with colocalized immunoreactivity (arrows) and one in which $\mathrm{Na}^{+}$channel label was absent (arrowhead). e, $f$, A P14 optic nerve, double-labeled with ankyrin-3/G $(e)$ and $\mathrm{Na}^{+}$channel $(f)$ antibodies. $g$, At P13, some nodes had a gap between the intense nodal and weaker paranodal ankyrin-3/G staining (arrowhead). $h$, In adults, small-caliber axons (arrow) had prominent paranodal ankyrin-3/G, but larger axons did not (arrowhead). Scale bars, $10 \mu \mathrm{m}$.

localized at nodes of Ranvier (Kordeli et al., 1995). Furthermore, it has been suggested that the neuronal cytoskeleton may intrinsically determine the location of nodes and direct the clustering of $\mathrm{Na}^{+}$channels (Kaplan et al., 1997). At P7, ankyrin-3/G staining overlapped with the edges of MAG-labeled oligodendrocyte processes (Fig. 5a,b), a distribution that was similar to that of Caspr immunoreactivity (Fig. 1d). By P9, $\mathrm{Na}^{+}$channel clusters (Fig. 5d, arrow) were detected that corresponded with the middle of ankyrin-3/G immunoreactivity (Fig. 5c, arrow). However, the ankyrin-3/G staining extended beyond the $\mathrm{Na}^{+}$channel cluster into both paranodal regions. Figure $5 c$ also shows an ankyrin-3/ G-labeled site without any accompanying $\mathrm{Na}^{+}$channel immuno- 
reactivity (arrowhead). Furthermore, ankyrin-3/G immunolabel could be seen to extend into the internode in a thin, spiral line (Fig. 5c, arrowhead). This pattern closely resembles that of the Caspr-labeled zone seen in peripheral nerve and may represent the inner mesaxon (Scherer et al., 1998). At P9, 8 of 22 sites with ankyrin-3/G had some colocalized $\mathrm{Na}^{+}$channel immunoreactivity, but the remaining 14 sites did not. In contrast, $\mathrm{Na}^{+}$channel clusters were never seen in the absence of ankyrin-3/G staining.

At later stages of development (P14), there was some variability in the distribution of ankyrin-3/G. Seventy-five percent (136 of 181) of ankyrin-3/G-labeled sites included overlapping $\mathrm{Na}^{+}$channel immunoreactivity at the center. As seen for $\mathrm{Na}^{+}$channels, ankyrin-3/G labeling was present only in regions that were surrounded by MAG immunofluorescence (data not shown). Occasionally there was a distinct gap in ankyrin-3/G staining (Fig. 5e, arrowhead). In these cases, $\mathrm{Na}^{+}$channels colocalized with one (Fig. 5f, arrowhead) or both (data not shown) edges of the ankyrin-3/G-labeled zone. At other sites, the ankyrin-3/G immunoreactivity was found in two discrete locations. Figure $5 g$ shows a P13 rat optic nerve labeled for ankyrin-3/G. Several sites are present, but one region (arrowhead) shows intense nodal staining, with clear, but much weaker, ankyrin-3/G labeling in the paranodes. Distinct gaps in fluorescence are present on either side of the node. The function of paranodal ankyrin-3/G is unknown, but this distribution has also been reported in some nerve fibers in the PNS (Kordeli et al., 1990). In adults, ankyrin-3/G immunofluorescence was most intense at nodes but was still detectable through paranodes (Fig. 5h). One interesting observation was that paranodal staining was more prominent in smaller-diameter fibers (Fig. 5h, arrow).

\section{Shiverer mutant mice}

The results reported thus far suggested that clustering of $\mathrm{Na}^{+}$ channels in the optic nerve is mediated by interaction with myelinating oligodendrocytes. As an additional test, we examined clustering in the hypomyelinating mouse mutant Shiverer (Shi). Shi mice suffer from a deletion of five of six exons in the myelin basic protein (MBP) gene, resulting in loss of compact CNS myelin (Roach et al., 1985). Axons may be ensheathed by multiple lamellae of oligodendroglial processes, but myelin is not uniformly compacted, and axoglial junctions are irregular in shape, size, and distribution (Rosenbluth, 1980, 1981; Inoue et al., 1981). Optic nerves from Shi (Fig. 6a) and control littermates (Fig. 6b) at P23 were both prominently labeled for MAG, indicating that there are large numbers of oligodendrocytes in the Shi optic nerve. However, MAG was less uniformly distributed in Shi, an observation that is consistent with the myelin abnormalities. Some individual oligodendrocytes had increased levels of MAG expression with pronounced cytoplasmic, perinuclear staining (Fig. 6a, arrowhead; Sheedlo and Siegel, 1987).

Shi optic nerve preparations were also double-labeled for $\mathrm{Na}^{+}$ channels and Caspr immunoreactivity. In adult controls, $\mathrm{Na}^{+}$ channel clusters were focal and were bordered by well defined regions of Caspr immunofluorescence at all nodes of Ranvier (Fig. $6 d$ ). In contrast, the $\mathrm{Na}^{+}$channel immunoreactivity in adult Shi optic nerves was irregular, often forming short comma-shaped structures or thin elongated zones (Fig. 6c). When focal $\mathrm{Na}^{+}$ channel clusters were present, they were usually bordered by zones of Caspr immunoreactivity (Fig. 6c,e, arrowhead). The Caspr staining sometimes partially surrounded the $\mathrm{Na}^{+}$channel cluster, as seen in Figure $6 f$ (asterisk). Pairs of Caspr-labeled paranodes were seldom seen, but single abnormal axoglial junc- tional zones were abundant (Fig. 6c). These $\mathrm{Na}^{+}$channel and Caspr distributions appear similar to the "lakes" of particle patches and irregular axoglial junctions described by Rosenbluth (1981) in a freeze fracture study of Shi CNS. In adult Shi, $24 \%$ of $\mathrm{Na}^{+}$channel clusters, all of which were aberrant in distribution, were without any adjacent Caspr immunoreactivity (Fig. $6 c$, twin arrows). Compared with sections of normal mouse optic nerves, however, this represents only $5 \%$ of the number of sites per FOV. Ankyrin-3/G staining in control littermate optic nerve was identical to that seen in the rat, with an intensely labeled nodal region, and weaker immunofluorescence in the paranodes (shown with corresponding $\mathrm{Na}^{+}$channel labeling in Fig. 7c,d). In contrast, Figure 7, $a$ and $b$, shows that ankyrin-3/G distributions in adult Shi mutant mice were very disrupted and did not form any structures that can be identified as nodes of Ranvier. During development in Shi, ankyrin-3/G staining was not localized in nodal aggregates at any age (data not shown).

Does the lack of $\mathrm{Na}^{+}$channel clusters seen in adult shi optic nerves result from a progressive loss of normal node-like distributions, or is their absence a consequence of failure to form proper axoglial junctions? To help answer this question, we counted the number of clusters at several ages during development. $\mathrm{Na}^{+}$channel immunoreactivity was categorized as either relatively normal and focal (node-like), usually in association with a Caspr-labeled paranode (Fig. 6e, arrowhead), or aberrant (Fig. $6 f$ ). At all ages after their initial detection, the Shi mutant had dramatically reduced numbers of node-like $\mathrm{Na}^{+}$channel clusters (Fig. $8 a, \diamond)$. P52 control littermates had an average of 59 clusters per FOV (Fig. $8 a, \mathbf{\square} ; n=8$ ), and the general trend of clustering throughout development closely matched that in the rat optic nerve (Fig. 4a). By comparison, P52 Shi mice had only three focal aggregates per FOV $(n=5)$. In all FOVs from Shi mutants additional immunolabeled regions were seen but were aberrant in shape (Fig. $8 a, \mathbf{\Delta}$ ). Thus, even at the earliest stages of development the Shi mutant had clearly abnormal $\mathrm{Na}^{+}$channel clustering.

CAPs were measured, and corresponding conduction velocities were calculated throughout development in both Shi and control mice. There was a slight increase in conduction velocity in Shi mice, from P10 to P20, probably because of increased $\mathrm{Na}^{+}$ channel expression (Noebels et al., 1991), but velocities were always lower than in littermate controls (Fig. 8b). The CAP in control animals became multiphasic during the period of most rapid $\mathrm{Na}^{+}$channel clustering, paranode formation, and myelination (Fig. 8c), as was the case seen above in normal rats (Fig. 4d). In contrast, records from Shi nerves always had just a single component (Fig. 8c).

\section{DISCUSSION}

There is evidence from both electrical and immunocytochemical experiments that the gradient in $\mathrm{Na}^{+}$channel density at the node is very sharp (Shrager, 1989; Dugandzija-Novakovic et al., 1995). What mechanisms are responsible for the clustering of $\mathrm{Na}^{+}$ channels during node formation? Currently, there are two main hypotheses that have experimental support. The first suggests that the establishment and spacing of $\mathrm{Na}^{+}$channel clusters is under neuronal control and can occur independently of myelination. The second model asserts that clustering requires contact with myelinating glial cells (for review, see Salzer, 1997 and Vabnick and Shrager, 1998). Independent sets of experiments have suggested that in the sciatic nerve, during both remyelination and development, Schwann cells induce the aggregation of 

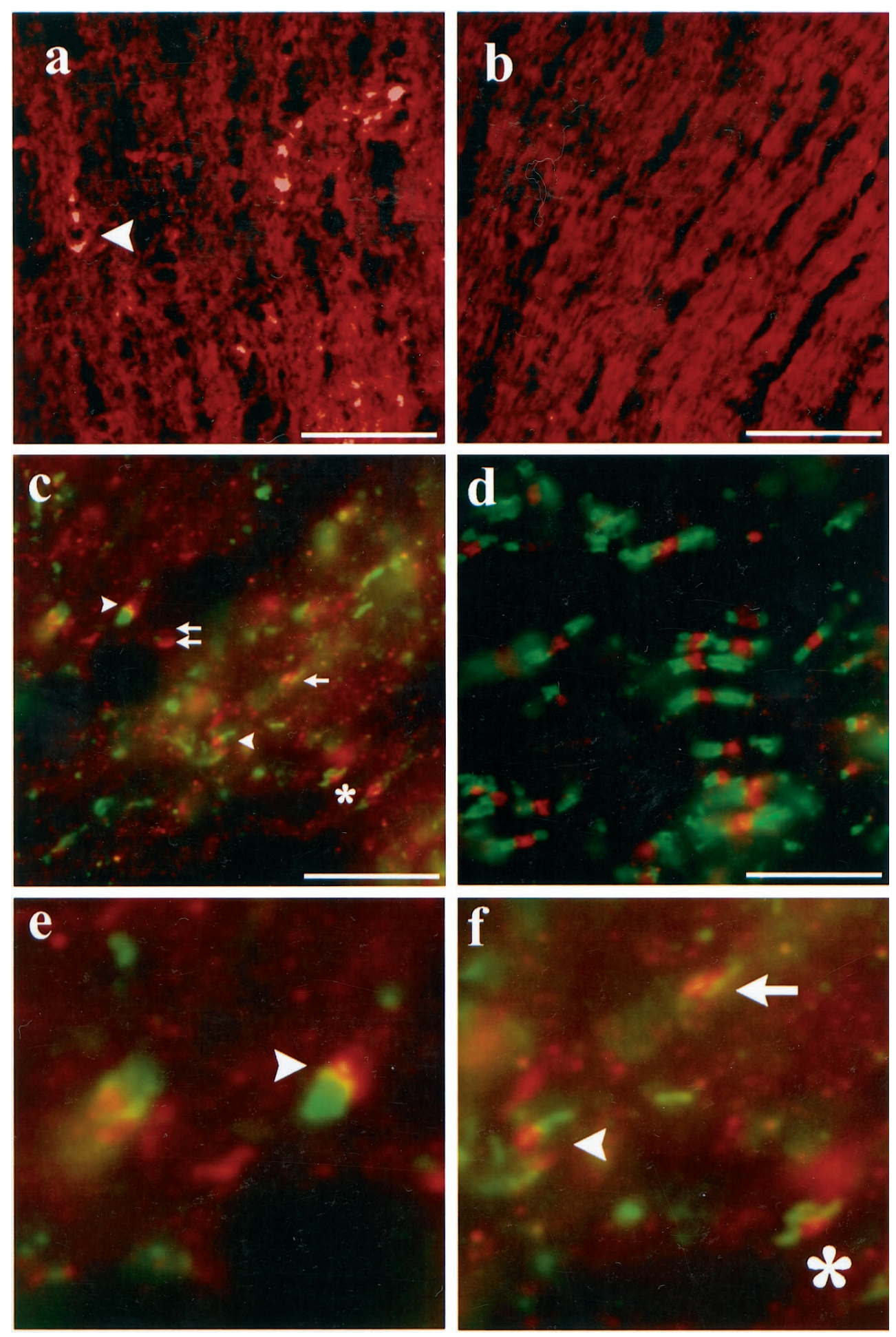

Figure 6. Optic nerves from adult Shiverer (Shi) mutant mice have severely disrupted $\mathrm{Na}^{+}$channel distributions and paranodal axoglial junctions. $a, b, \operatorname{Sh} i(a)$ and control littermate axons $(b)$ labeled for MAG. Oligodendrocytes from Shi cryosections often had elevated levels of this protein (a, arrowhead). $c, d$, Optic nerves from Shi (c) and control littermate $(d)$ mice double-labeled to indicate $\mathrm{Na}^{+}$channels (red), and Caspr (green). $e$, Focal $\mathrm{Na}^{+}$channel cluster (red, arrowhead) flanked on one side by Caspr label (green) in Shi. f, Caspr (green) and $\mathrm{Na}^{+}$channel (red) immunoreactivity seen in non-nodal distributions in Shi. Caspr and $\mathrm{Na}^{+}$channel staining was usually seen together in adjacent but not overlapping distributions (see Results). Scale bars, $10 \mu \mathrm{m}$.

$\mathrm{Na}^{+}$channels, perhaps by excluding them from regions of close axoglial contact, and thereby direct the location of nodes (Dugandzija-Novakovic et al., 1995; Novakovic et al., 1996; Vabnick et al., 1996; Koszowski et al., 1998). From the finding that $\mathrm{Na}^{+}$channel clusters were invariably associated with MAGpositive processes, it was further concluded that Schwann cells must ensheathe axons and commence myelination before they direct clustering (Martini and Schachner, 1986; Vabnick et al., 1996). Other research led to a very different conclusion, that the axon independently specified the location of nodes of Ranvier and initiated channel aggregation (England et al., 1990; Deerinck et al., 1997; Lambert et al., 1997).

All of this work, however, was done in the peripheral nervous system. What happens in the CNS? Thus far, the main evidence has come from the in vitro experiments of Kaplan et al. (1997), in which retinal ganglion cells were suspended above a noncontacting layer of optic nerve glia. An increase in the occurrence of regularly spaced clusters of sodium channels was seen on ganglion cell axons when oligodendrocytes but not astrocytes were used. Clusters also formed when the neurons were grown in glial- 

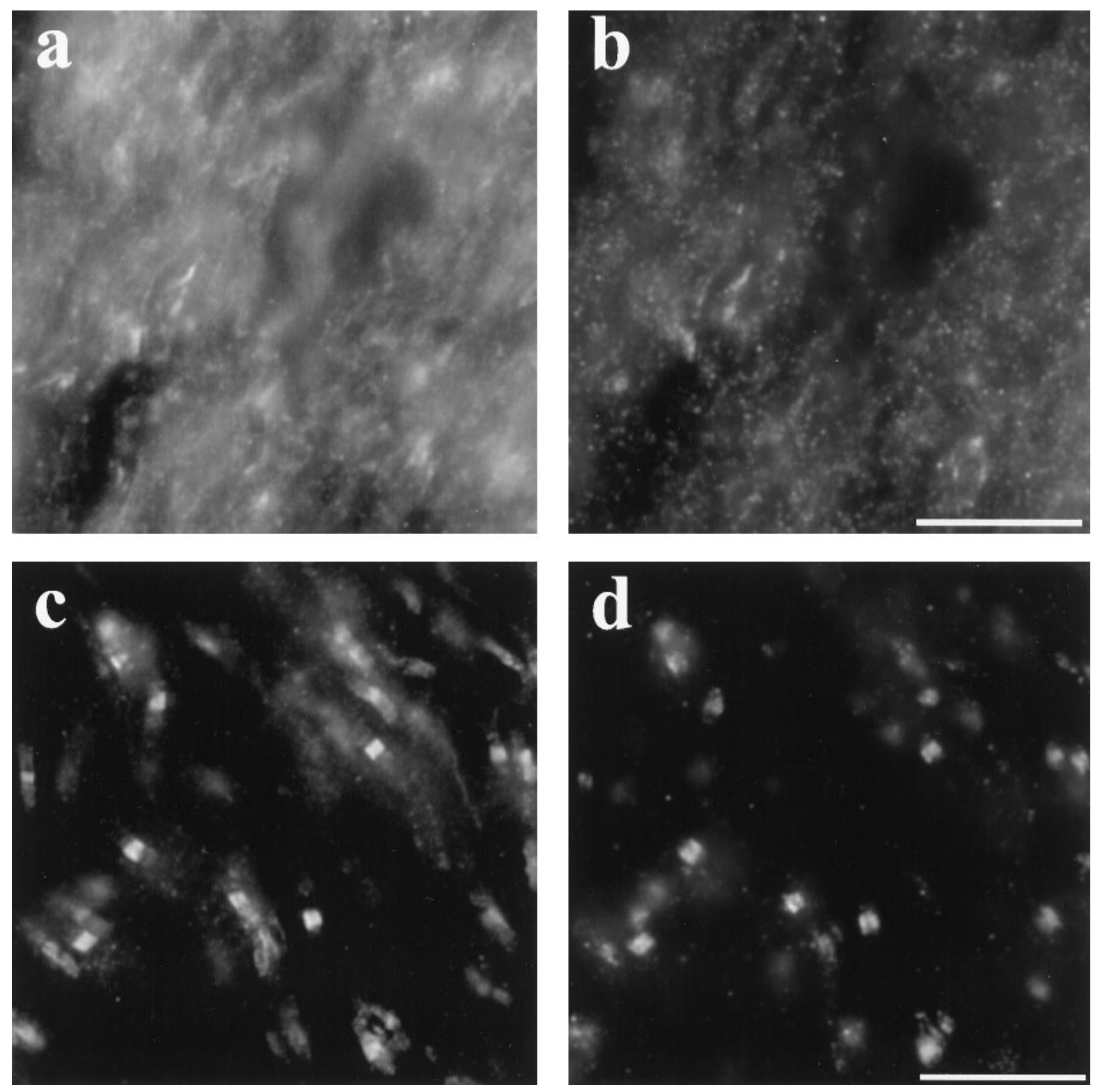

Figure 7. Abnormal ankyrin-3/G distributions in Shi mutant mice. $a$, Ankyrin-3/G immunoreactivity in adult Shi mutant mice appeared random and disorganized. $b, \mathrm{Na}^{+}$channel staining of the same section. Littermate control mice had normal ankyrin-3/G $(c)$ and $\mathrm{Na}^{+}$channel $(d)$ labeling. Scale bars, $10 \mu \mathrm{m}$.

conditioned media. Because these effects were independent of direct axon-glial contact, it was concluded that ganglion cell axons determine the site of nodal cluster formation and that the role of a putative secreted glial factor was to induce channel clustering at these predetermined sites. In the present study, we have followed these same axons in vivo.

\section{Interactions with oligodendrocytes}

We have shown that during development extensive MAGpositive oligodendrocyte processes pervade the optic nerve before the earliest detection of $\mathrm{Na}^{+}$channel immunoreactivity. $\mathrm{Na}^{+}$channels are known to be present in axons at this time (Waxman et al., 1989), and the presence of oligodendrocytes alone thus seems to be insufficient to induce aggregation to a level detectable by immunocytochemistry. When $\mathrm{Na}^{+}$channel clusters did appear, they were always in the unlabeled gap within MAGlabeled regions, consistent with the idea that glial contact is required for channel aggregation. There were, however, two problems with this argument. First, we could not always clearly associate a cluster with a specific MAG-positive process. Second, in contrast to the peripheral nervous system, in which MAG expression signals the commitment of a Schwann cell to myelination (Martini and Schachner, 1986), in the CNS this glycoprotein is present on the surface of oligodendrocytes before axonal ensheathement (Bartsch et al., 1989).

To better define early stages of myelination we examined the expression of Caspr, a component of the paranodal septate-like junctions (Einheber et al., 1997). In this case, we were able to judge colocalization within the same axon much more clearly. We have shown that $88 \%$ of the first detectable $\mathrm{Na}^{+}$channel clusters were bordered on at least one side by Caspr-labeled paranodes. Furthermore, $\mathrm{Na}^{+}$channels were always excluded from Casprpositive paranodes, suggesting a process similar to that hypothe- 
a

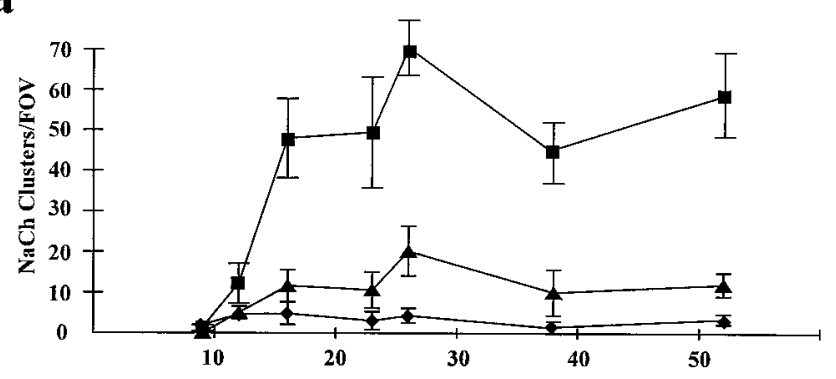

b

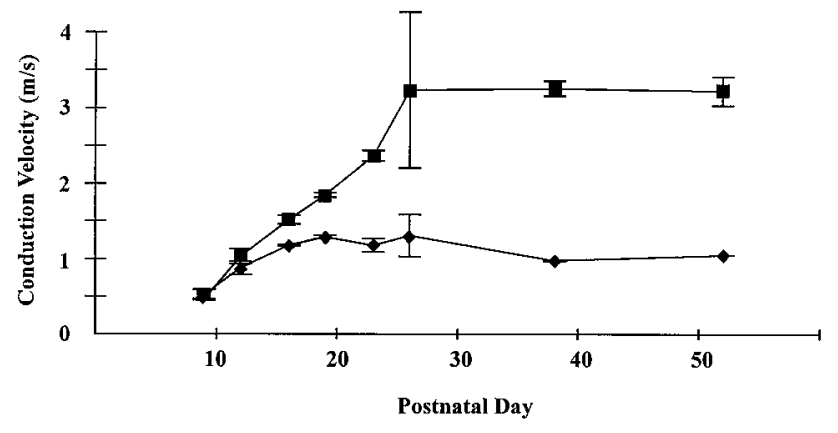

c

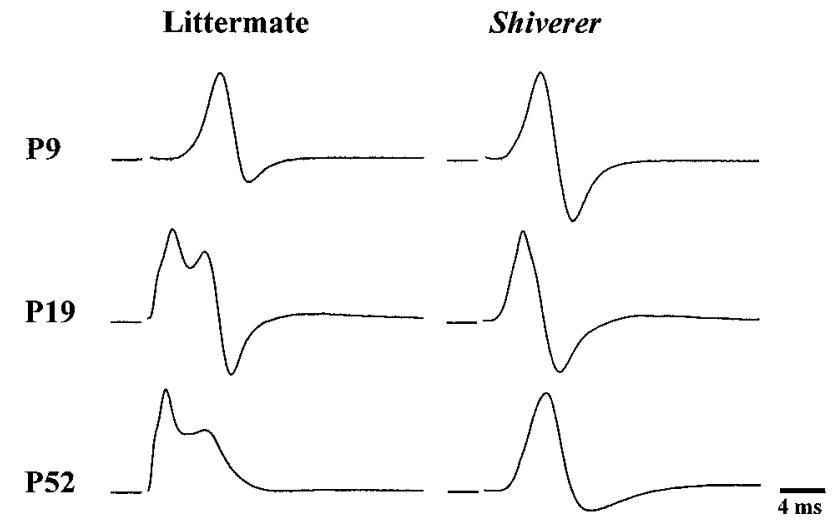

Figure 8. $\mathrm{Na}^{+}$channel clusters, conduction velocities, and CAPs in Shi mutant mice. $a$, Number of normal $\mathrm{Na}^{+}$channel clusters per FOV for $S h i$ $(\checkmark)$ and control littermates (ם). Abnormally shaped $\mathrm{Na}^{+}$channel clusters in $S h i$ were also plotted $(\boldsymbol{\Delta})$. b, Conduction velocities in Shi $(\downarrow)$ and control littermates ( $\mathbf{\square}$ ) plotted as a function of age at $37^{\circ} \mathrm{C}$. c, Optic nerve CAPs at P9, P19, and P52 in Shi and wild-type littermates. Error bars in $a$ and $b$ indicate SD.

sized in the PNS. If, however, this latter model is applicable to the optic nerve, then how does one explain the $12 \%$ of sites at which $\mathrm{Na}^{+}$channels were not associated with Caspr? Axoglial junctions begin to form after the first glial rotation (Wiggins et al., 1988), and it is possible that this minimal structure is not detected by immunocytochemistry, but is sufficient to initiate clustering. We recognize, however, that although comprising only a small percentage, the presence of these sites introduced some uncertainty in the interpretation. Thus, as a further test, a hypomyelinating mutant was examined.

Shiverer mice have MAG-positive oligodendrocytes that may ensheathe axons (Rosenbluth, 1980; Inoue et al., 1981) but lack functional MBP (Dupouey et al., 1979; Roach et al., 1985) and do not form compact myelin (Privat et al., 1979). If $\mathrm{Na}^{+}$channel clustering depends only on the presence of oligodendrocytes and is independent of myelin and oligodendroglial contact, one would expect to find normal channel distributions in Shi mice, but this was not the case. We have shown that there were far fewer $\mathrm{Na}^{+}$ channel clusters than in control littermates, and those clusters that did form were often highly irregular. Similarly, Caspr-positive axoglial junctions were distorted. Importantly, in $\sim 75 \%$ of cases, misshapen $\mathrm{Na}^{+}$channel clusters were adjacent to highly irregular Caspr-labeled zones. Despite this disruption, $\mathrm{Na}^{+}$channels did not overlap with Caspr at these sites. These results are consistent with a mechanism in which the formation of axoglial junctions at paranodes plays a major role in the aggregation of axonal $\mathrm{Na}^{+}$ channels at nodes of Ranvier.

A minority of $\mathrm{Na}^{+}$channel clusters in Shi did not fit the "contact" hypothesis. We found that one-fourth of the irregular sites seen in adult Shi mice were not associated with Casprlabeled axoglial junctions. However, it is important to note that these sites represent only $5 \%$ of the normal number of clusters per FOV seen in control littermates. It is possible that some of the aberrant paranodes are unstable and degenerate, leaving transient isolated clusters. Alternatively, there may be sites at which $\mathrm{Na}^{+}$channels cluster in the absence of direct glial contact. These zones have also been described in a number of situations, including demyelinated axons in fish (England et al., 1990), premyelinated mouse sciatic axons (Vabnick et al., 1997), axons of dystrophic mice (Deerinck et al., 1997), and neurites from an invertebrate (Johnston et al., 1996). However, in all these cases clusters were either transient or at distances inappropriate for nodes of Ranvier. It has been suggested that a high local concentration of channels may result in some intrinsic clustering (Vabnick and Shrager, 1998), and that this may even be the default distribution in some unmyelinated axons (Johnston et al., 1996). In fact, $\mathrm{Na}^{+}$channel expression in Shi optic nerves, as measured by saxitoxin binding, is increased to $470 \%$ of controls (Noebels et al., 1991), and this may enhance the likelihood of some spontaneous aggregation. Furthermore, we speculate that the soluble "clustering" factor released by oligodendrocytes in vitro (Kaplan et al., 1997) may act by upregulating $\mathrm{Na}^{+}$channel synthesis. Channel aggregation may then follow secondarily to the increased membrane expression. There is at least a partial precedent for this mechanism because exposure of PC12 cells to nerve growth factor increases brain type II $\mathrm{Na}^{+}$channel expression (Mandel et al., 1988), the same channel that is upregulated in Shi mutant mice (Westenbroek et al., 1992).

Although a small fraction of sites remain unexplained, the results strongly suggest a mechanism in which the development of nodes of Ranvier begins with the formation of axoglial junctions at the edges of oligodendrocyte processes. These structures then induce the clustering of axonal $\mathrm{Na}^{+}$channels at high density, perhaps by exclusion from regions of close contact. Oligodendrocytes may additionally modulate $\mathrm{Na}^{+}$channel expression or axonal transport through non-contact-dependent mechanisms. It should also be noted that astrocyte processes abut many CNS nodes of Ranvier but have not been shown to influence ion channel segregation at this site.

\section{Molecular interactions with $\mathrm{Na}^{+}$channels at the node of Ranvier}

Ankyrin-3/G is an attractive candidate to mediate the clustering of $\mathrm{Na}^{+}$channels (Srinivasan et al., 1992, Kordeli et al., 1995, Zhou et al., 1998). We have shown that during myelination in the optic nerve ankyrin-3/G immunoreactivity precedes $\mathrm{Na}^{+}$channel detection, appearing first in paranodal zones, and later extending through the nodal gap. $\mathrm{Na}^{+}$channel immunofluorescence always 
colocalized with nodal ankyrin-3/G staining but never extended into the paranode. Importantly, the ankyrin-binding cell adhesion molecule neurofascin is enriched at the node and colocalizes with both ankyrin-3/G and $\mathrm{Na}^{+}$channels (Lambert et al., 1997) but also extends into paranodal zones (Davis et al., 1996). Kordeli et al. (1990) described punctate paranodal ankyrin-3/G labeling in adult sciatic nerves. Consequently, because this cytoskeletal protein extends into non-nodal regions throughout development, it is not likely to be the primary determinant of $\mathrm{Na}^{+}$channel clustering. Instead, because ankyrin-3/G immunoreactivity is most intense within the nodal gap, it may function to maintain the integrity of $\mathrm{Na}^{+}$channel clusters after localization at nodes. Indeed, after demyelination in the PNS, nodal $\mathrm{Na}^{+}$channel clusters remain intact for at least 1 week (Dugandzija-Novakovic et al., 1995), but juxtaparanodal $\mathrm{K}^{+}$channels, which do not bind ankyrin-3/G, are rapidly dispersed (Rasband et al., 1998). Finally, the normal pattern of ankyrin-3/G staining is highly disrupted in Shi mice, indicating that localization of axonal ankyrin-3/G also depends on cooperation with myelinating oligodendrocytes.

\section{REFERENCES}

Bartsch U, Kirchhoff F, Schachner M (1989) Immunohistological localization of the adhesion molecules L1, N-CAM, and MAG in the developing and adult optic nerve of mice. J Comp Neurol 284:451-462.

Bekele-Arcuri Z, Matos MF, Manganas MM, Strassle BW, Monaghan MM, Rhodes KJ, Trimmer JS (1996) Generation and characterization of subtype-specific monoclonal antibodies to $\mathrm{K}+$ channel alpha and beta subunit polypeptides. Neuropharmacology 35:851-865.

Black JA, Foster RE, Waxman SG (1982) Rat optic nerve: freeze-fracture studies during development of myelinated axons. Brain Res 250:1-20.

Butt AM, Ransom BR (1993) Morphology of astrocytes and oligodendrocytes during development in the intact rat optic nerve. J Comp Neurol 338:141-158.

Chiu SY, Ritchie JM (1980) Potassium channels in nodal and internodal axonal membrane of mammalian myelinated fibres. Nature 284:170-171.

Chiu SY, Ritchie JM (1981) Evidence for the presence of potassium channels in the paranodal region of acutely demyelinated mammalian single nerve fibres. J Physiol (Lond) 313:415-437.

Davis JQ, Lambert S, Bennett V (1996) Molecular composition of the node of Ranvier: identification of ankyrin-binding cell adhesion molecules neurofascin (mucin+/third FNIII domain-) and NrCAM at nodal axon segments. J Cell Biol 135:1355-1367.

Deerinck TJ, Levinson SR, Bennett GV, Ellisman MH (1997) Clustering of voltage-sensitive sodium channels on axons is independent of direct Schwann cell contact in the dystrophic mouse. J Neurosci 17:5080-5088.

Dugandzija-Novakovic S, Koszowski AG, Levinson SR, Shrager P (1995) Clustering of $\mathrm{Na}$ channels and node of Ranvier formation in remyelinating axons. J Neurosci 15:492-502.

Dupouey P, Jacque C, Bourre JM, Cesselin F, Privat A, Baumann N (1979) Immunochemical studies of the basic protein in Shiverer mouse devoid of major dense line of myelin. Neurosci Lett 12:113-118.

Einheber S, Zanazzi G, Ching W, Scherer S, Milner TA, Peles E, Salzer JL (1997) The axonal membrane protein Caspr, a homologue of neurexin IV, is a component of the septate-like paranodal junctions that assemble during myelination. J Cell Biol 139:1495-1506.

England JD, Gamboni F, Levinson SR, Finger TE (1990) Changed distribution of sodium channels along demyelinated axons. Proc Natl Acad Sci USA 87:6777-6780.

Foster RE, Connors BW, Waxman SG (1982) Rat optic nerve: electrophysiological, pharmacological and anatomical studies during development. Brain Res 255:371-386.

Fukuda Y, Hsiao CF, Watanabe M, Ito H (1984) Morphological correlates of physiologically identified $\mathrm{Y}-, \mathrm{X}-$, and $\mathrm{W}$-cells in cat retina. J Neurophysiol 52:999-1013.

Hildebrand C, Waxman SG (1984) Postnatal differentiation of rat optic nerve fibers: electron microscopic observations on the development of nodes of Ranvier and axoglial relations. J Comp Neurol 224:25-37.

Hsiao CF, Watanabe M, Fukuda Y (1984) The relation between axon diameter and axonal conduction velocity of $\mathrm{Y}, \mathrm{X}$ and $\mathrm{W}$ cells in the cat retina. Brain Res 309:357-361.

Inoue Y, Nakamura R, Mikoshiba K, Tsukada Y (1981) Fine structure of the central myelin sheath in the myelin deficient mutant Shiverer mouse, with special reference to the pattern of myelin formation by oligodendroglia. Brain Res 219:85-94.

Johnston WL, Dyer JR, Castellucci VF, Dunn RJ (1996) Clustered voltage gated Na channels in Aplysia axons. J Neurosci 16:1730-1739.

Kaplan MR, Meyer-Franke A, Lambert S, Bennett V, Duncan ID, Levinson SR, Barres BA (1997) Induction of sodium channel clustering by oligodendrocytes. Nature 386:724-728.

Kordeli E, Davis J, Trapp B, Bennett V (1990) An isoform of ankyrin is localized at nodes of Ranvier in myelinated axons of central and peripheral nerves. J Cell Biol 110:1341-1352.

Kordeli E, Lambert S, Bennett V (1995) AnkyrinG. A new ankyrin gene with neural-specific isoforms localized at the axonal initial segment and node of Ranvier. J Biol Chem 270:2352-2359.

Koszowski AG, Owens GC, Levinson SR (1998) The effect of the mouse mutation claw paw on myelination and nodal frequency in sciatic nerves. J Neurosci 18:5859-5868.

Lambert S, Davis JQ, Bennett V (1997) Morphogensis of the node of Ranvier: coclusters of ankyrin and ankyrin binding integral proteins define early developmental intermediates. J Neurosci 15:7025-7036.

Mandel G, Cooperman SS, Maue RA, Goodman RH, Brehm P (1988) Selective induction of brain type II Na+ channels by nerve growth factor. Proc Natl Acad Sci USA 85:924-928.

Martini R, Schachner M (1986) Immunoelectron microscopic localization of neural cell adhesion molecules (L1, N-CAM, and MAG) and their shared carbohydrate epitope and myelin basic protein in developing sciatic nerve. J Cell Biol 103:2439-2448.

Menegoz M, Gaspar P, Le Bert M, Galvez T, Burgaya F, Palfrey C, Ezan P, Arnos F, Girault JA (1997) Paranodin, a glycoprotein of neuronal paranodal membranes. Neuron 19:319-331.

Mi H, Deerinck TJ, Ellisman MH, Schwarz TL (1995) Differential distribution of closely related potassium channels in rat Schwann cells. J Neurosci 15:3761-3774.

Noebels JL, Marcom PK, Jalilian-Tehrani MH (1991) Sodium channel density in hypomyelinated brain increased by myelin basic protein gene deletion. Nature 352:431-434.

Novakovic SD, Deerinck TJ, Levinson SR, Shrager P, Ellisman MH (1996) Clusters of axonal $\mathrm{Na}+$ channels adjacent to remyelinating Schwann cells. J Neurocytol 25:403-412.

Peles E, Nativ M, Lustig M, Grumet M, Schilling J, Martinez R, Plowman GD, Schlessinger J (1997) Identification of a novel contactinassociated transmembrane receptor with multiple domains implicated in protein-protein interactions. EMBO 16:978-988.

Peters LL, John KM, Lu FM, Eicher EM, Higgins A, Yialamas M, Turtzo LC, Otsuka AJ, Lux SE (1995) Ank3 (epithelial ankyrin), a widely distributed new member of the ankyrin gene family and the major ankyrin in kidney, is expressed in alternatively spliced forms, including forms that lack the repeat domain. J Cell Biol 130:313-330.

Poltorak M, Sadoul R, Keilhauer G, Landa C, Fahrig T, Schachner M (1987) Myelin-associated glycoprotein, a member of the L2/HNK-1 family of neural cell adhesion molecules, is involved in neuronoligodendrocyte and oligodendrocyte-oligodendrocyte interaction. J Cell Biol 105:1893-1899.

Privat A, Jacque C, Bourre JM, Dupouey P, Baumann N (1979) Absence of the major dense line in myelin of the mutant mouse "shiverer." Neurosci Lett 12:107-112.

Rasband MN, Trimmer JS, Schwarz TL, Levinson SR, Ellisman MH, Schachner M, Shrager P (1998) Potassium channel distribution, clustering, and function in remyelinating rat axons. J Neurosci 18:36-47.

Roach A, Takahashi N, Pravtcheva D, Ruddle F, Hood L (1985) Chromosomal mapping of mouse myelin basic protein gene and structure and transcription of the partially deleted gene in shiverer mutant mice. Cell 42:149-155.

Rosenbluth J (1980) Central myelin in the mouse mutant shiverer. J Comp Neurol 194:639-648.

Rosenbluth J (1981) Axoglial junctions in the mouse mutant Shiverer. Brain Res 208:283-297.

Salzer JL (1997) Clustering sodium channels at the node of Ranvier: close encounters of the axon-glia kind. Neuron 18:843-846.

Scherer SS, Xu YT, Zhou L, Chiu SY (1998) Myelinating Schwann cells determine the internodal localization of Kv1.1 and Kv1.2, and Caspr/ Paranodin. Soc Neurosci Abstr 24:1026.

Schnapp B, Peracchia C, Mugnaini E (1976) The paranodal axo-glial junction in the central nervous system studied with thin sections and freeze-fracture. Neurosci 1:181-190. 
Sheedlo HJ, Siegel GJ (1987) Comparison of the distribution of $\mathrm{Na}+, \mathrm{K}+$-ATPase and myelin-associated glycoprotein (MAG) in the optic nerve, spinal cord and trigeminal ganglion of shiverer (shi/shi) and control $(+/+)$ mice. Brain Res 415:105-114.

Shrager P (1989) Sodium channels in single demyelinated mammalian axons. Brain Res 483:149-154.

Skoff RP, Price DL, Stocks A (1976) Electron microscopic autoradiographic studies of gliogenesis in rat optic nerve. II. Time of origin. J Comp Neurol 169:313-334.

Srinivasan Y, Elmer L, Davis J, Bennett V, Angelides K (1988) Ankyrin and spectrin associate with voltage-dependent sodium channels in brain. Nature 333:177-180.

Srinivasan Y, Lewallen M, Angelides KJ (1992) Mapping the binding site on ankyrin for the voltage-dependent sodium channel from brain. J Biol Chem 267:7483-7489.

Stys PK, Ransom BR, Waxman SG (1991) Compound action potential of nerve recorded by suction electrode: a theoretical and experimental analysis. Brain Res 546:18-32.

Trimmer JS, Trowbridge IS, Vacquier VD (1985) Monoclonal antibody to a membrane glycoprotein inhibits acrosome reaction and associated $\mathrm{Ca}^{++}$and $\mathrm{H}^{+}$fluxes of sea urchin sperm. Cell 40:697-703.

Trimmer JS, Cooperman SS, Tomiko SA, Zhou JY, Crean SM, Boyle MB, Kallen RG, Sheng ZH, Barchi RL, Sigworth FJ, Goodman RH, Agnew WS, Mandel G (1989) Primary structure and functional expression of a mammalian skeletal muscle sodium channel. Neuron 3:33-49.
Vabnick I, Shrager P (1998) Ion channel redistribution and function during development of the myelinated axon. J Neurobiol 37:80-96.

Vabnick I, Novakovic SD, Levinson SR, Schachner M, Shrager P (1996) The clustering of axonal sodium channels during development of the peripheral nervous system. J Neurosci 16:4914-4922.

Vabnick I, Messing A, Chiu SY, Levinson SR, Schachner M, Roder J, Li C, Novakovic S, Shrager P (1997) Sodium channel distribution in axons of hypomyelinated and MAG null mutant mice. J Neurosci Res 50:321-336.

Wang H, Kunkel DD, Martin TM, Schwartzkroin PA, Tempel BL (1993) Heteromultimeric $\mathrm{K}+$ channels in terminal and juxtaparanodal regions of neurons. Nature 365:75-79.

Waxman SG, Black JA, Kocsis JD, Ritchie JM (1989) Low density of sodium channels supports action potential conduction in axons of neonatal rat optic nerve. Proc Natl Acad Sci USA 86:1406-1410.

Westenbroek RE, Noebels JL, Catterall WA (1992) Elevated expression of type II $\mathrm{Na}+$ channels in hypomyelinated axons of shiverer mouse brain. J Neurosci 12:2259-2267.

Wiggins RC, Chongjie G, Delaney C, Samorajski T (1988) Development of axonal-oligodendroglial relationships and junctions during myelination of the optic nerve. Int J Dev Neurosci 6:233-243.

Zhou D, Lambert S, Malen PL, Carpenter S, Boland LM, Bennett V (1998) Ankyrin-G is required for clustering of voltage-gated Na channels at axon initial segments and for normal action potential firing. J Cell Biol 143:1295-1304. 